\title{
ZONEAMENTO DE PARÂMETROS CLIMÁTICOS PARA A VERTENTE PARANAENSE DA BACIA HIDROGRÁFICA DO RIO ITARARÉ \\ ZONING OF CLIMATIC PARAMETERS TO THE PARANÁ SLOPE OF ITARARÉ WATERSHED
}

\author{
Paulo Miguel De Bodas Terassi ${ }^{1}$, José Tadeu Garcia Tommaselli ${ }^{2}$ \\ ${ }^{1}$ Universidade de São Paulo (USP), São Paulo, SP, Brasil \\ 2 Universidade Estadual Paulista "Júlio de Mesquita Filho" (UNESP), Presidente Prudente, SP, Brasil
}

Correspondência para: Paulo Miguel De Bodas Terassi (pmbterassi@gmail.com)

doi: 10.12957/geouerj.2017.22422

Recebido em: 11 abr. 2016 | Aceito em: 15 jul. 2017

\section{RESUMO}

O clima funciona como um insumo de energia para a bacia hidrográfica e desempenha o papel de controlar ou influenciar diversos componentes da dinâmica socioambiental desse recorte espacial. Dessa forma, o presente trabalho objetiva propor o zoneamento climático da área de estudo e identificar prováveis problemas ambientais decorrentes dos diferentes regimes climáticos. Foram obtidos os dados anuais e mensais de chuva de treze postos pluviométricos junto ao Instituto das Águas do Paraná e de uma estação meteorológica, de Joaquim Távora, pertencente ao Instituto Agronômico do Paraná, para o segmento temporal de 1976 a 2012. Foram utilizadas as seguintes metodologias: o índice de erosividade de Rufino, Biscaia e Merten (1993); as estimativas de temperatura fornecidas pela Universidade de Delaware (2014); e o balanço hídrico climatológico de Thornthwaite e Mather (1955). O zoneamento climático permitiu averiguar a relação das características climáticas com os componentes socioambientais da área de estudo. A zona climática IV merece atenção por ter apresentado a maior erosividade das chuvas junto à verificação de solo exposto, fatores que representam maior susceptibilidade à erosão. A zona climática I apresenta a significativa ocupação por pastagens e lavouras temporárias e a possibilidade de deficiência hídrica demonstra uma vulnerabilidade a essas atividades econômicas.

Palavras-chave: zonas climáticas; bacia hidrográfica; erosividade; balanço hídrico climatológico.

\begin{abstract}
The climate works as an energy input to the watershed and plays the role of controlling and influencing various components of the dynamics socio-environmental of this spatial cutout. Thus, the present study aims to propose the climatic zoning of the study area and identify potential environmental problems arising from different climatic regimes. Were obtained the annual and monthly rain data of thirteen rain gauge stations along with the Paraná Institute of Water and the weather station Joaquim Távora, which belongs to the Agronomic Institute of Paraná, for the time segment from 1976 to 2012. The following methodologies were used: erosivity indices of Rufino, Biscaia and Merten (1993); Temperature estimates provided by the University of Delaware (2014); climatic water balance of Thornthwaite and Mather (1955). The climatic zoning made it possible to examine the relation between the climatic characteristics and the social-environmental components of the study area. The climate zone IV requires attention for presenting the highest rainfall erosivity besides the exposed soil, factors that evince the greatest vulnerability to erosion. The climate zona I presents significant occupancy of pastures and temporary crops, and the warning of the possibility of deficiency water demonstrates a vulnerability to these economic activities.
\end{abstract}

Keywords: Climate zones; watershed; erosivity; climatic water balance.

\section{INTRODUÇÃO}


O clima é um dos componentes de maior importância da dinâmica ambiental pela sua interferência em diversos setores das atividades sociais e econômicas e por sua interação com os demais atributos de uma paisagem (SANT'ANNA NETO, 2008). As características climáticas de determinada região são mensuradas por seus atributos, que refletem a relação entre os fatores constituintes do clima (APARECIDO et al., 2016).

As informações sobre o regime pluviométrico contribuem para a tomada de decisões em áreas estratégicas para o desenvolvimento econômico e social, como por exemplo, na geração de energia elétrica, nas atividades industriais e no planejamento agrícola (CLARKE; SILVA, 2004). Uma das principais características da pluviometria é a sua potencialidade em ocasionar erosões, denominada de erosividade, considerada uma das forças ativas na formação dos processos erosivos, a partir do impacto de suas gotículas em determinada porção de solo (SILVA, 2004; VITTE; MELLO, 2007). Outro elemento climático, a temperatura é indispensável para a realização do balanço hídrico climatológico, que contabiliza a quantidade de água que entra e sai de certa porção de solo em um determinado intervalo de tempo (PEREIRA, 2005). As informações resultantes do balanço hídrico têm utilidade na definição dos setores e dos períodos de maiores problemas hídrico, seja pela da deficiência ou pelo excesso hídrico e, portanto, essenciais para o planejamento de segmentos como a agricultura e a gestão de recursos hídricos (CAMARGO; CAMARGO, 2000; WREGE et al., 2016).

Os estudos dos aspectos físicos e sociais existentes em bacias hidrográficas permitem avaliar os seus diversos componentes, os processos e interações que nela ocorrem (SANTOS, 2004). Especificamente, o clima corresponde a um insumo de energia para as bacias hidrográficas e responde diretamente pela qualidade e quantidade dos recursos hídricos, revelando associações entre a pluviosidade e o potencial erosivo das chuvas, que possibilitam recomendações diretas de práticas preditivas para as perdas de solo, e as características termo-pluviométricas e a disponibilidade hídrica, fatores importantes para o monitoramento dos recursos hídricos. 
Dessa forma, o presente trabalho objetiva propor o zoneamento climático da área de estudo a partir da análise qualitativa e quantitativa dos resultados, conjugando-os aos demais aspectos físicos e sociais que compõe a área de estudo, e identificar prováveis problemas ambientais decorrentes dos diferentes regimes climáticos.

\section{LOCALIZAÇÃO E CARACTERIZAÇÃO DA ÁREA DE ESTUDO}

A porção paranaense da bacia hidrográfica do rio Itararé está situada entre os Primeiro, Segundo e Terceiro Planaltos Paranaenses (MAACK, 2012), entre as coordenadas UTM 625000 e 675000 Em e 7420000 e $7300000 \mathrm{Nm}$, especificamente na zona 22S. A área da bacia abrange uma superfície aproximada de 4.845 km2 (ITCG, 2014) e localiza-se nos setores nordeste do estado do Paraná (Figura 1).

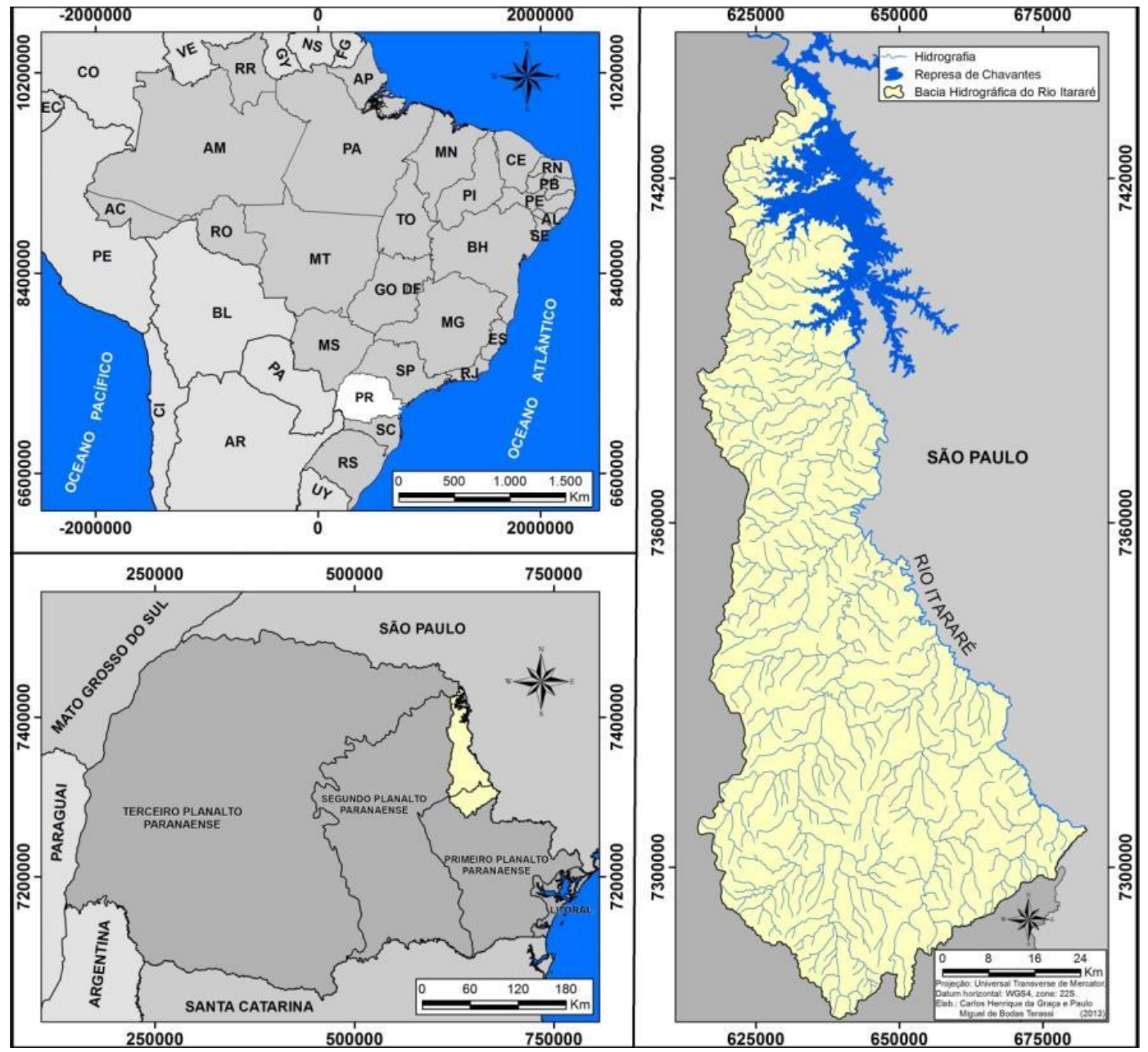

Figura 1- Localização da vertente paranaense da bacia hidrográfica do rio itararé 
A vertente paranaense da bacia hidrográfica do rio Itararé é composta por uma elevada diversidade de unidade litoestratigráficas, que vão desde as rochas formadas no Proterozóico Superior predominantes no setor Sul, do Grupo Açungui e do Complexo Cunhaporanga, às formações do período Mesozóico, dentre elas, Pirambóia, Botucatu e Serra Geral (MINEROPAR, 2001). Nos setores de maiores declividades, superiores a 20\%, predominam os Cambissolos Háplicos e os Neossolos Litólicos, sendo que em setores de declives variáveis entre $8 \%$ a $20 \%$ predominam os Nitossolos Vermelhos e o Argissolos Vermelhos-Amarelos. Os Latossolos Vermelhos recobrem os setores de declividades inferiores a 8\% (EMBRAPA, 2007).

Os estudos de Terassi e Tommaselli (2015) indicaram que porção oeste e central da vertente paranaense da bacia hidrográfica do rio Itararé caracteriza-se por um clima subtropical mesotérmico úmido (Cfb), de temperatura do mês mais frio inferior a $18{ }^{\circ} \mathrm{C}$ e temperatura do mês mais quente inferior a $22{ }^{\circ} \mathrm{C}$, enquanto que o setor norte, com as mais elevadas temperaturas, obteve a tipologia climática Cfa, que designa um clima subtropical quente úmido, de temperatura do mês mais frio inferior a $18{ }^{\circ} \mathrm{C}$ e temperatura do mês mais quente superior a $22{ }^{\circ} \mathrm{C}$, sendo verificada a inexistência de estação seca definida para toda da área em estudo.

\section{MATERIAIS E MÉTODOS}

Obtiveram-se os dados de treze postos pluviométricos junto ao Instituto das Águas do Paraná e de uma estação meteorológica da rede do Instituto Agronômico do Paraná, em Joaquim Távora, trabalhados com segmento temporal de 1976 a 2012. Os dados dos postos pluviométricos que estão ao entorno da bacia hidrográfica foram utilizados na busca de uma melhor distribuição espacial da precipitação pluviométrica e para o preenchimento de dados faltantes (Tabela 1 - Figura 2).

\begin{tabular}{c|c|c|c|c|c}
\hline Número & Código da & Posto Pluviométrico/ Estação & Latitude & Longitude & Altitude \\
ANEEL & Meteorológica & (S) & $(\mathbf{W})$ & $(\mathbf{m})$ \\
\hline 1 & 02349060 & Carlópolis (Nova Brasília) & 7395526 & 627900 & 563 \\
\hline 2 & 02449030 & Castro (Fazenda Marão) & 7275043 & 633292 & 1100 \\
\hline 3 & 02449021 & Doutor Ulysses (Varzeão) & 7282084 & 660061 & 818 \\
\hline 4 & 02449036 & Jaguariaíva (Eduardo Xavier da Silva) & 7302629 & 643698 & 1000 \\
\hline 5 & 02449040 & Jaguariaíva & 7317956 & 630287 & 890 \\
\hline
\end{tabular}




\begin{tabular}{c|c|c|c|c|c}
\hline 6 & 02349030 & Joaquim Távora* & 7400672 & 615718 & 512 \\
\hline 7 & 02449011 & Piraí do Sul & 7286806 & 608541 & 1068 \\
\hline 8 & 02449032 & Piraí do Sul (Capinzal) & 7289831 & 629085 & 1026 \\
\hline 9 & 02349036 & Ribeirão Claro & 7433790 & 627919 & 782 \\
\hline 10 & 02349061 & Santana do Itararé & 7372279 & 640380 & 543 \\
\hline 11 & 02349064 & São José da Boa Vista & 7354589 & 637409 & 550 \\
\hline 12 & 02449045 & São José da Boa Vista (Barra Mansa) & 7337733 & 637247 & 850 \\
\hline 13 & 02449044 & Sengés & 7333850 & 655848 & 650 \\
\hline 14 & 02349033 & Tomazina & 7371211 & 606992 & 483 \\
\hline
\end{tabular}

Tabela 1 - Localização geográfica dos postos pluviométricos e estação Meteorológica* na vertente paranaense da bacia hidrográfica do rio Itararé.

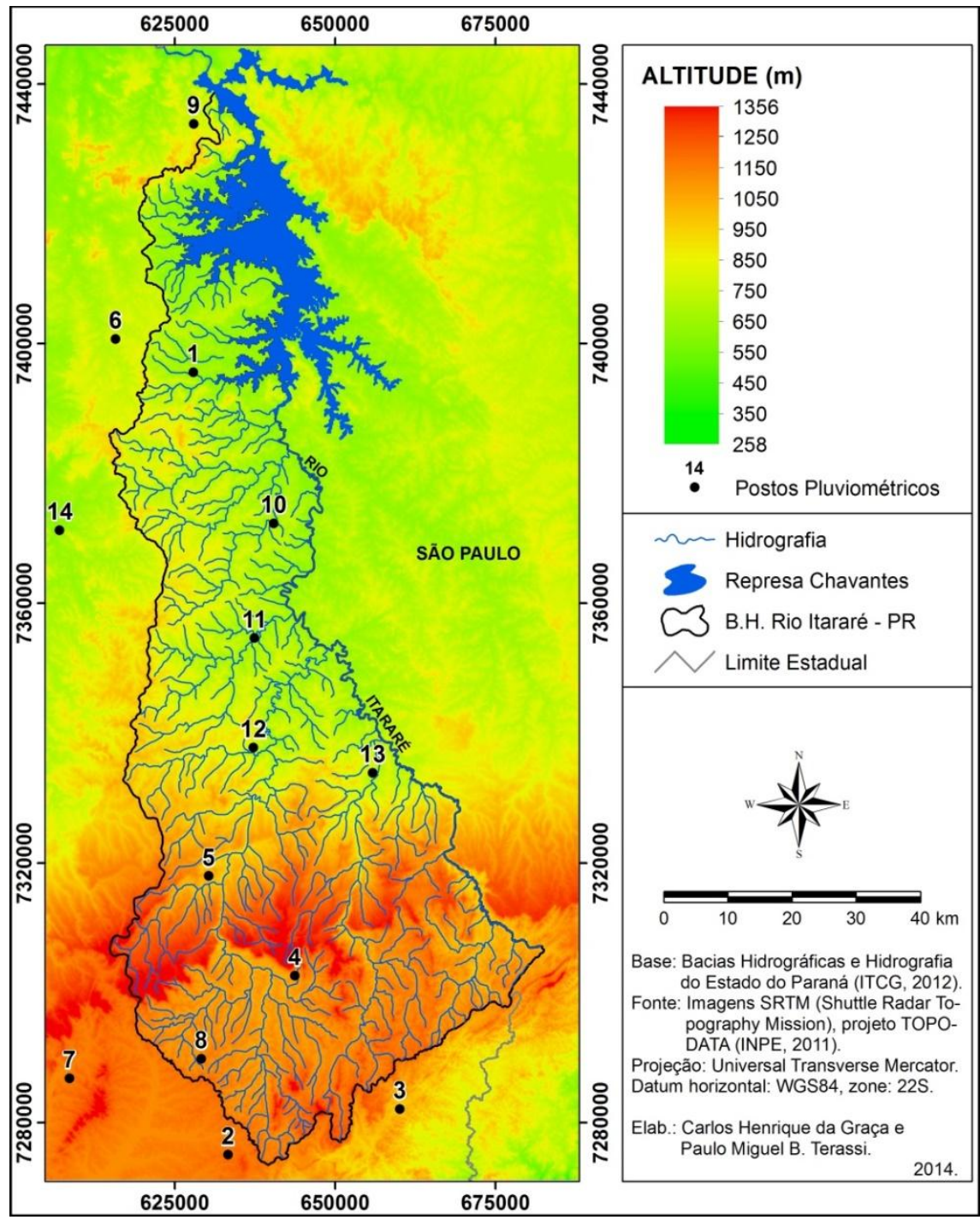

Figura 2 - Localização geográfica e hipsometria da estação meteorológica e dos postos pluviométricos para a vertente paranaense da bacia hidrográfica do rio Itararé - PR

Para a melhor manipulação e organização das informações foi realizado tratamento dos dados de precipitação utilizando de parâmetros estatísticos básicos em planilha eletrônica Microsoft Office Excel 2007. Os dados faltantes dos postos pluviométricos e estações meteorológicas foram preenchidos 
seguindo o método de ponderação regional apresentado por Villela e Mattos (1975). Esse método tem como base o registro pluviométrico de três postos localizados o mais próximo possível do posto em que se verifica a falta de dados (OLIVEIRA et al., 2010), com características pluviométricas (distribuição mensal e os totais anuais) e altitudes semelhantes.

O índice de erosividade da chuva foi calculado utilizando os dados de precipitação média mensal e média anual obtidos para a área de estudo, aplicando a equação do tipo $\mathrm{Y}=\mathrm{a}+\mathrm{bx}$, onde: $\mathrm{Y}=$ índice de erosão (MJ.mm.ha-1.h-1.ano-1); $\quad$ a e $b=$ coeficientes linear e angular, e $x=p 2 / P$, apresentada por Rufino, Biscaia e Merten (1993) na identificação de regiões isoerosivas no estado do Paraná. Os valores atribuídos nesse estudo encontram-se na região isoerosiva 7 ( $\mathrm{Y}=9,51+4,20 \mathrm{x}$ ), que deu parâmetro para a Equação 2. Como os valores do índice erosão encontrados para cada estação pluviométrica são expressos na escala mensal, foi necessária a soma dos índices mensais para obtenção dos valores anuais.

$$
\text { 『"EI" 』_"m" "=9,51+4,20" }\left(\mathrm{p}^{\wedge} 2 / \mathrm{P}\right)^{\wedge}(* 9,80665)
$$

Onde: EIm - Índice mensal de erosividade da chuva em MJ.mm.ha-1.h-1.mês-1; a - coeficiente linear; $\quad b$ - coeficiente angular; $\quad$ p - Precipitação média mensal em milímetros; $\mathrm{P}$ - Precipitação média anual em milímetros; 9, 80665 - Conversão Kgf.m para MJ.

Os dados de temperatura foram obtidos da estação meteorológica de Joaquim Távora. Para as demais áreas da bacia hidrográfica foram atribuídos os valores de temperatura fornecidos pela Universidade de Delaware, sendo que se utilizaram os dados referentes ao segmento temporal de 1976 a 2010 (UDEL, 2014). Devido à inexistência dos dados de temperatura para os anos de 2011 e 2012, foram realizadas estimativas de temperatura média através do método de Ometto (1981), que considera uma variação de $0,65^{\circ} \mathrm{C}$ a cada 100 metros de altitude.

Com os valores de temperatura, foi possível a obtenção do balanço hídrico climatológico, realizado a partir do método proposto por Thornthwaite e Mather (1955), com o auxílio do programa "BHnorm" 
elaborado em planilha eletrônica por Rolim et al. (1998), e tendo como parâmetro o CAD (capacidade de água disponível) de $100 \mathrm{~mm}$.

Para a definição das zonas climáticas, realizou-se o emprego da técnica de agrupamento, com a finalidade de compreender os parâmetros climáticos de forma conjunta aos fatores geográficos do clima, dentre eles a altitude, latitude e circulação atmosférica, e demais elementos climáticos associados. Seguiu-se como principal critério a pluviosidade mensal, uma vez que este elemento climático apresentou uma maior associação com os parâmetros climáticos erosividade e excedente hídrico, considerados fundamentais para a análise do zoneamento climático e a sua relação com os usos e tipos de ocupação do solo.

Adotou-se o método de ligação hierárquico Ward, que mensura a distância entre dois grupos pela soma de desvios ao quadrado dos pontos ao centróide. Como as variáveis classificatórias utilizadas nesse estudo são variáveis reais, adotou-se a medida da distância Euclidiana, mais adequada às características das variáveis em análise (KELLER FILHO; ASSAD; LIMA, 2006; FRITZSONS et al., 2011; TEODORO et al., 2015). Utilizou-se o software Statistica versão 7.0 para o processo de análise cluster e para a sua representação gráfica a partir da elaboração do gráfico denominando dendograma, ou árvore de ligação, o qual apresenta um resumo do método aplicado, considerando desde o passo inicial, unindo os primeiros dois objetos, até o passo final no qual todos os elementos foram agrupados constituindo um único grupo (Figura 3).

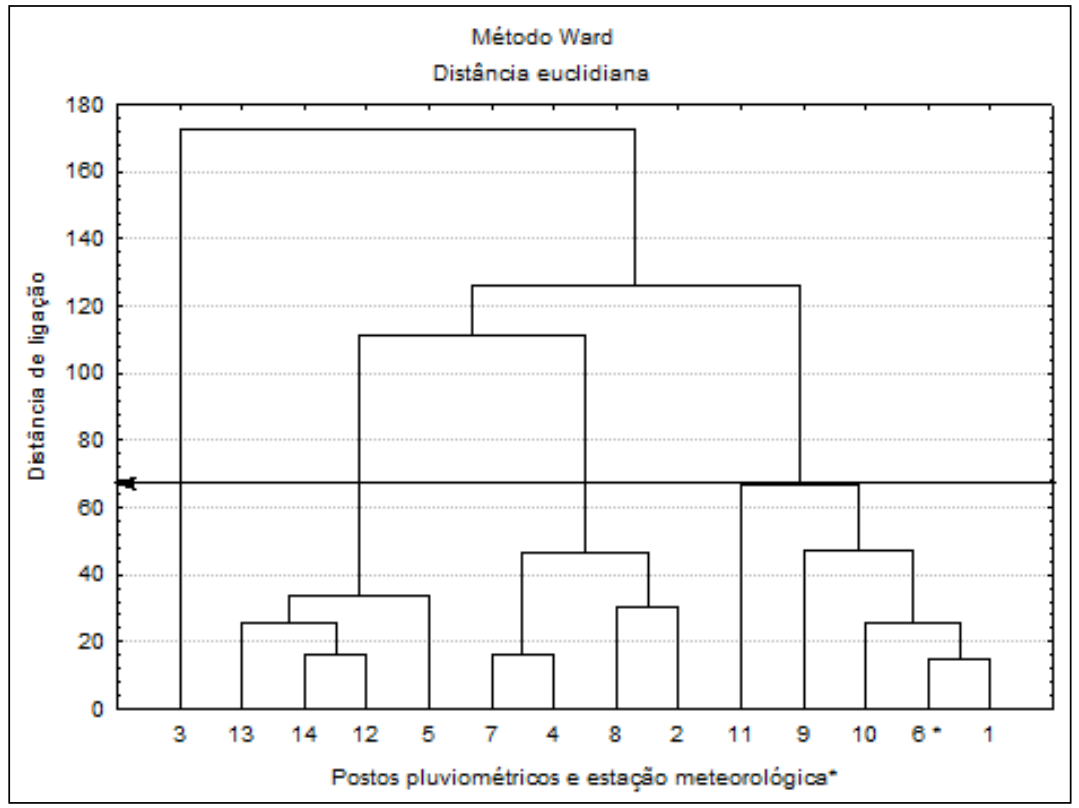


Figura 3 - Dendograma da pluviosidade média mensal para os postos pluviométricos e a estação meteorológicas inseridos dentro e no entorno da bacia hidrográfica do rio Itararé - PR.

As cartas de localização dos postos pluviométricos e do zoneamento climático tiveram como parâmetro principal a hipsometria, a qual foi dada a partir de informações das imagens SRTM (Shuttle Radar Topography Mission) (INPE, 2011). De posse das imagens SRTM, que recobrem a área da bacia hidrográfica do rio Itararé (PR), foi possível a elaboração destas cartas no aplicativo ArcGis versão 10.3. A carta de cobertura vegetal e uso da terra foi elaborada por meio de imagens de satélite LandSat 8 sensor TM que são distribuídas gratuitamente via sitio eletrônico do Instituto de Pesquisas Espaciais (INPE) e, posteriormente foram classificados os elementos das imagens por máxima verossimilhança no aplicativo ENVI versão 5.1.

\section{RESULTADOS E DISCUSSÕES}

O levantamento das características climáticas da área de estudo, especialmente com a delimitação de regiões homogêneas quanto aos atributos climáticos, aliado ao arcabouço teórico, permitiu identificar as zonas climáticas para a vertente paranaense da bacia hidrográfica do rio Itararé (Figura 4).

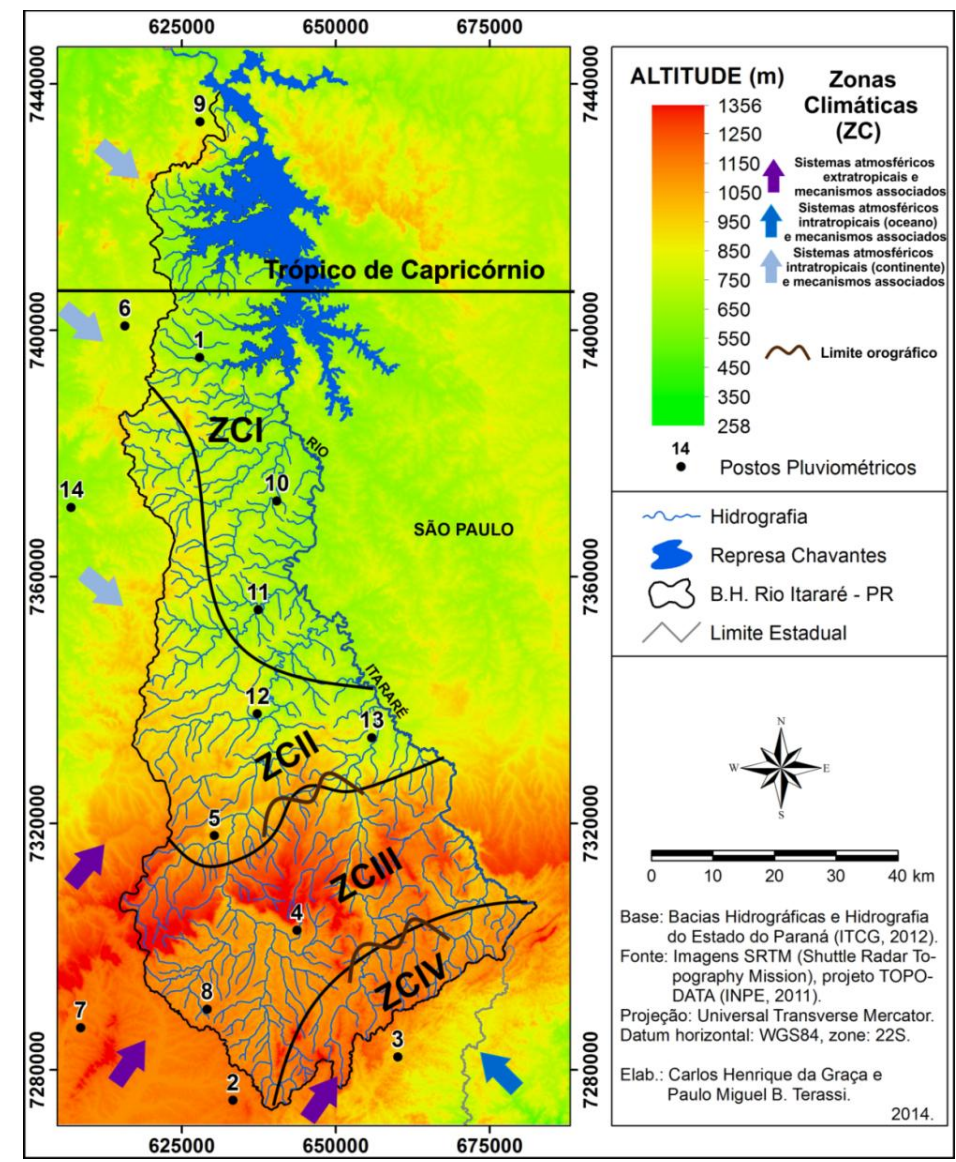


Figura 4 - Proposta de zoneamento climático para a bacia hidrográfica do rio Itararé - PR.

A zona climática I corresponde ao setor norte e leste da bacia hidrográfica. Caracteriza-se pela menor pluviosidade média anual e o menor número de dias de chuva, resultante da combinação de menores altitudes com uma dinâmica atmosférica que apresenta a maior interferência de sistemas atmosféricos intertropicais. A obtenção de maiores valores do potencial erosivo anual em relação à zona climática III, essa última de maior hipsometria, se deve a maior concentração de pluviosidade em um número menor de dias de chuva, além da maior possibilidade de ocorrência de chuvas convectivas, essa última condição é atribuída ao aumento de temperaturas médias e evapotranspiração potencial e a maior participação dos sistemas atmosféricos intertropicais. Ainda, supõe-se que a represa de Chavantes pode configurar-se como um incremento da umidade regional, especialmente nos meses de verão, período de maior potencialidade da evapotranspiração e da formação de chuvas convectivas (Figuras 5 e 6).

Com o aumento da hipsometria média dos postos pluviométricos, a zona climática II apresentou um aumento de pluviosidade em relação à zona climática I. Considerando a proporção do acréscimo pluviométrico e do número de dias de chuva, comparativamente a zona climática I, essa porção da bacia hidrográfica caracteriza-se pelo maior potencial anual de erosividade das chuvas justamente pela combinação do aumento da altimetria, responsável pela formação de chuvas orográficas, e a sua posição geográfica, uma vez que se situa entre a zona climática I, marcada caracteristicamente pela maior participação dos sistemas atmosféricos intertropicais (continentais), e a zona climática III, onde se verificou características do regime de pluviosidade que indicam mais participação dos sistemas frontais (extratropicais). Principalmente, esse último aspecto revela que a zona climática II tem as maiores alturas pluviométricas e o maior potencial erosivo, sobretudo pela possibilidade de choques de massas de ar características distintas (Figuras 5 e 6 ).

A zona climática III obteve uma redução da pluviosidade média anual (mm) em relação à zona climática II por caracterizar-se pela maior participação de sistemas atmosféricos extratropicais e sua maior associação ao clima subtropical, de uma maior distribuição da pluviosidade sazonal e mensal, o 
que responde pelo menor potencial erosivo em relação às demais porções da bacia hidrográfica. Tratase da região que apresenta o limite do efeito orográfico, uma vez que apresenta uma média de altimetria de seus postos pluviométricos equivalente a 1046 metros, aspecto que determina menores médias térmicas e a diminuição da probabilidade da formação de chuvas convectivas. Proporcionalmente, a redução do potencial erosivo nessa região se dá pelo aumento do número de dias e a redução das alturas pluviométricas (Figuras 5 e 6 ).

A zona climática IV apresenta isoladamente a maior pluviosidade média anual, o maior número de dias de chuva e o maior potencial erosivo de toda bacia hidrográfica. Explica-se que a obtenção dos maiores valores para esse atributo climático se dá por uma condição semelhante ao observado para a zona climática II. A localização geográfica da bacia hidrográfica da zona climática IV permite compreendê-la como o limite de influência orográfica para a entrada de sistemas atmosféricos intertropicais oceânicos, especialmente a massa tropical atlântica $(\mathrm{mTa})$, que indicam o aumento local da ocorrência e do volume de pluviosidade e, consequentemente, do potencial erosivo das chuvas, principalmente no verão. No entanto, por sua situação meridional, a zona climática IV apresenta também uma maior influência da participação de sistemas atmosféricos extratropicais, o que a mantém com o maior potencial erosivo das chuvas inclusive em períodos que há uma habitual redução da erosividade para as demais porções da área de estudo (Figuras 5 e 6).

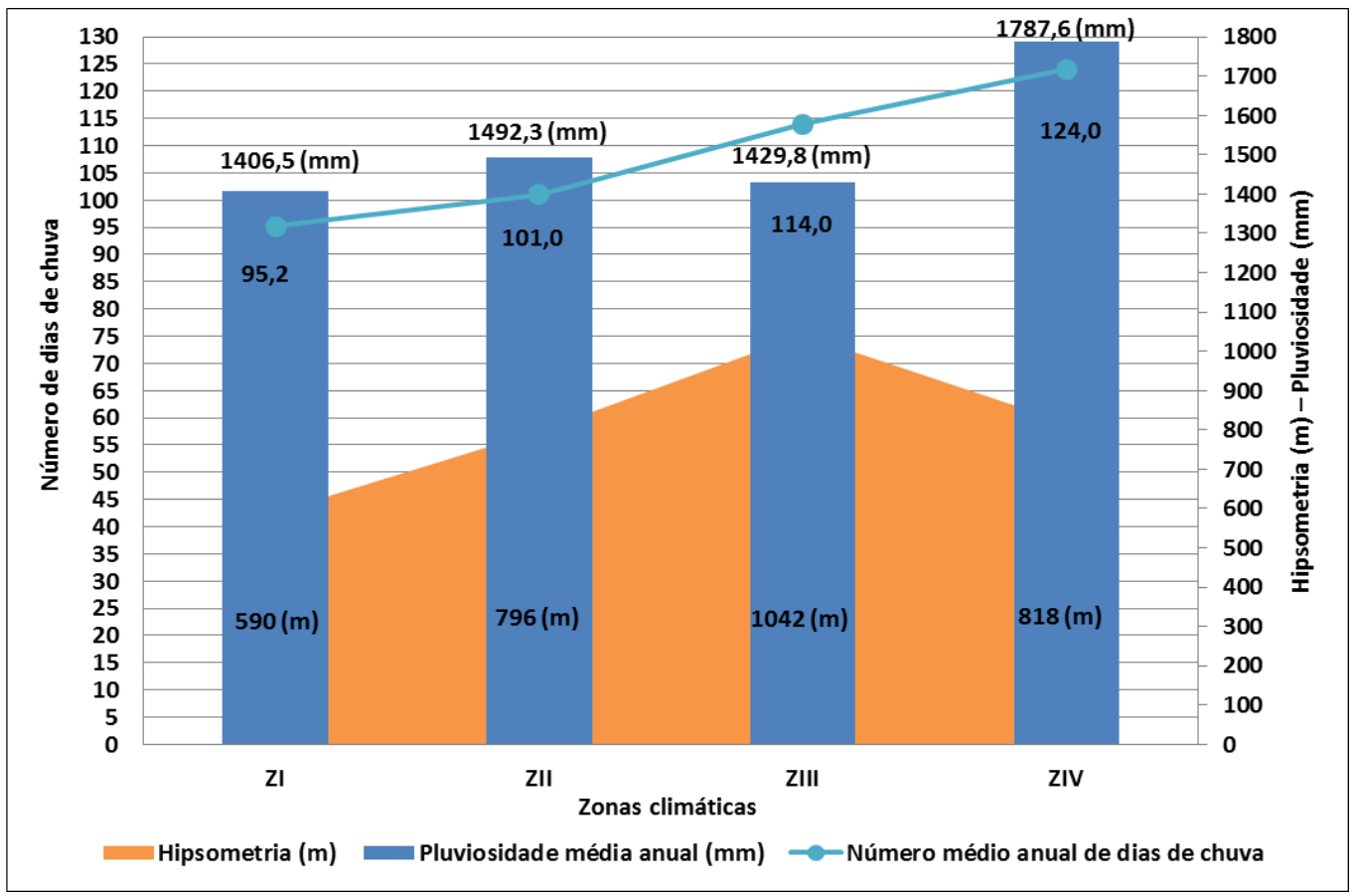


Figura 5 - Distribuição da pluviosidade média anual $(\mathrm{mm})$ e o número de dias de chuva conforme a altimetria e a zona climática da bacia hidrográfica do rio Itararé - PR.

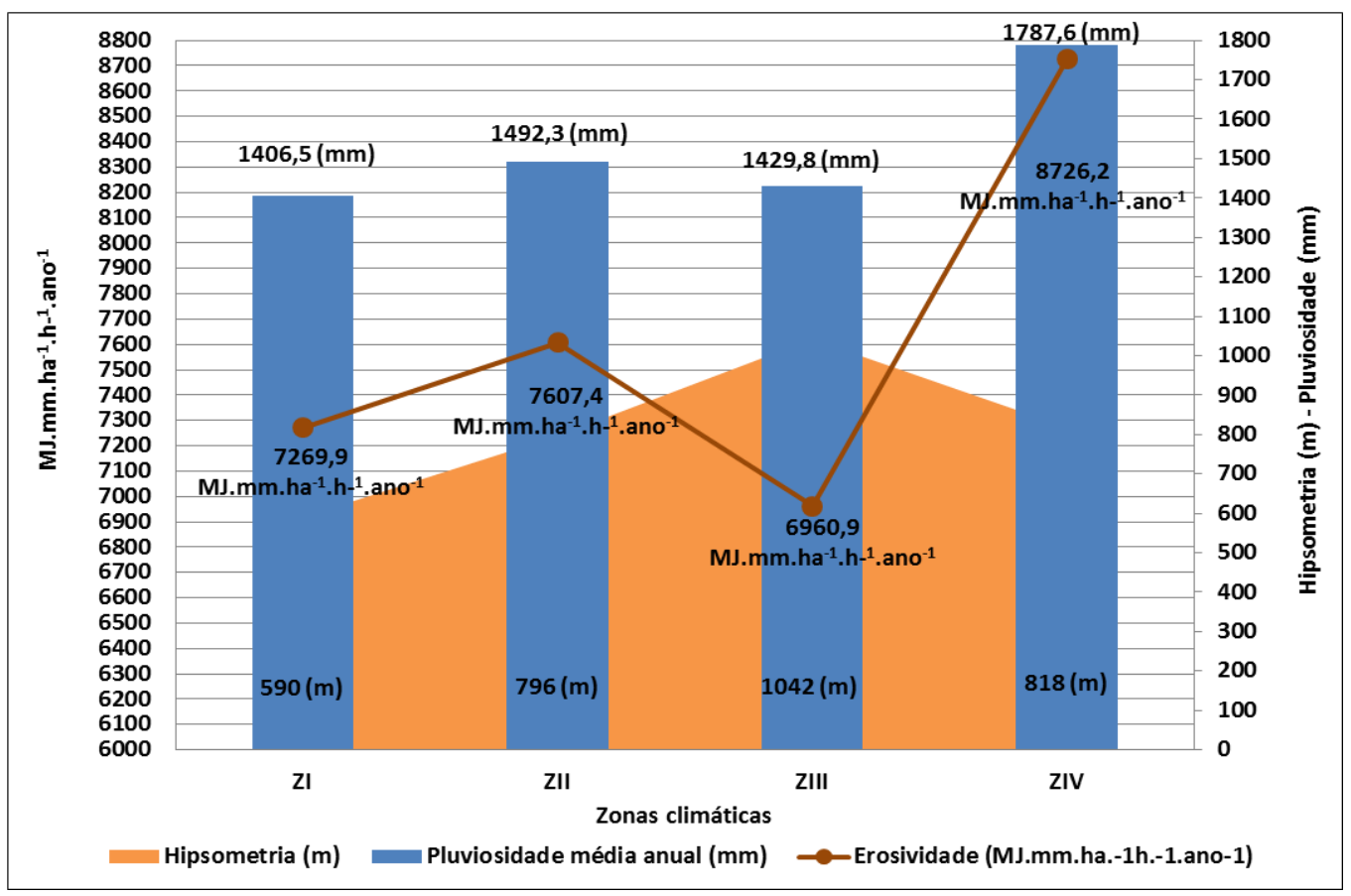

Figura 6 - Distribuição da pluviosidade média anual $(\mathrm{mm})$ e erosividade média anual conforme a altimetria e a zona climática da bacia hidrográfica do rio Itararé - PR.

Os resultados de pluviosidade indicaram concordância com o obtido por Correa (2013) para a bacia hidrográfica do rio Piquiri $(\mathrm{PR})$, que observou a influência da orografia para o acréscimo de pluviosidade entre o intervalo de altitudes entre 400 a 900 metros. Especialmente para os setores de maiores altimetrias, principalmente na porção central da área de estudo, a orografia perde o seu desempenho para as ocorrências de maiores alturas pluviométricas, o que se atribui a diminuição térmica e, consequentemente, do potencial de formação de chuvas convectivas.

A zona climática I corresponde ao setor em que se verificou de forma mais marcante o aumento de pluviosidade nos meses de verão e primavera, com uma concentração superior a $77 \%$ do potencial anual erosivo das chuvas no período que vai de janeiro a março e de outubro a dezembro. Consequentemente, essa porção da área de estudo apresenta a diminuição mais significativa dos índices de erosividade para o trimestre de junho, julho e agosto, que somados apresentam aproximadamente 10\% da média de erosividade anual (Figura 7). 
A zona climática II apresenta elevados valores de erosividade das chuvas nos meses de verão e primavera por receber influência direta das características pluviométricas dos sistemas atmosféricos intertropicais mais atuantes na zona climática I. No entanto, ao contrário do que ocorre no setor setentrional, apresenta uma regularidade das chuvas nos meses de outono e inverno por receber influência dos sistemas atmosféricos extratropicais, de maior atuação nos setores meridionais. Mormente, destaca-se que o período que vai de janeiro a março apresenta o equivalente a $45 \%$ da média anual de erosividade das chuvas para a região II (Figura 7).

A zona climática III é a porção do recorte de estudo com a maior regularidade anual da erosividade e a menor concentração do potencial erosivo nos meses que vai de janeiro a março e de outubro a dezembro, equivalente a $62 \%$. Considera-se que a zona climática III, mesmo com as maiores condições de hipsometria, obteve os menores valores de isoerodentes anuais devido à diminuição do potencial de chuvas convectivas próprias ao período de verão, uma vez que esta região apresenta as mais baixas médias térmicas da área de estudo (Figura 7).

A zona climática IV corresponde à porção da bacia hidrográfica com o maior potencial erosivo das chuvas por situar-se no limite do efeito orográfico, apresentando condições semelhantes às observadas para a zona climática II. No período que vai de setembro a março observa-se a concentração de $78 \%$ do potencial erosivo anual, sobretudo por sua condição de maiores probabilidades da ocorrência de chuvas convectivas, devido ao aumento de temperaturas médias em relação à zona climática III. No entanto, verifica-se que durante os meses de inverno e outono, devido à sua localização, esse setor mostra-se influenciável pelos sistemas atmosféricos extratropicais, fator que o mantém com uma elevada erosividade das chuvas para a série anual (Figura 7).

Nota-se que o período de janeiro a março e de setembro a outubro concentra o maior potencial erosivo para todos os grupos homogêneos, com uma relevante redução do índice de erosividade para o período de abril a agosto, principalmente para a zona climática I, região de maiores similaridades com o regime de chuvas do Brasil Tropical (NIMER, 1989). Os meses de maio e outubro apresentaram para as quatro zonas climáticas um aumento de pluviosidade em relação aos meses antecessores e sucessores, 
ressaltando a tendência de aumento do volume de pluviosidade atrelado à atuação associada de sistemas atmosféricos de origens e conteúdos distintos, uma vez que esses meses caracterizam-se pela transição de sazonalidades (WALTRICK et al., 2015) (Figura 7).

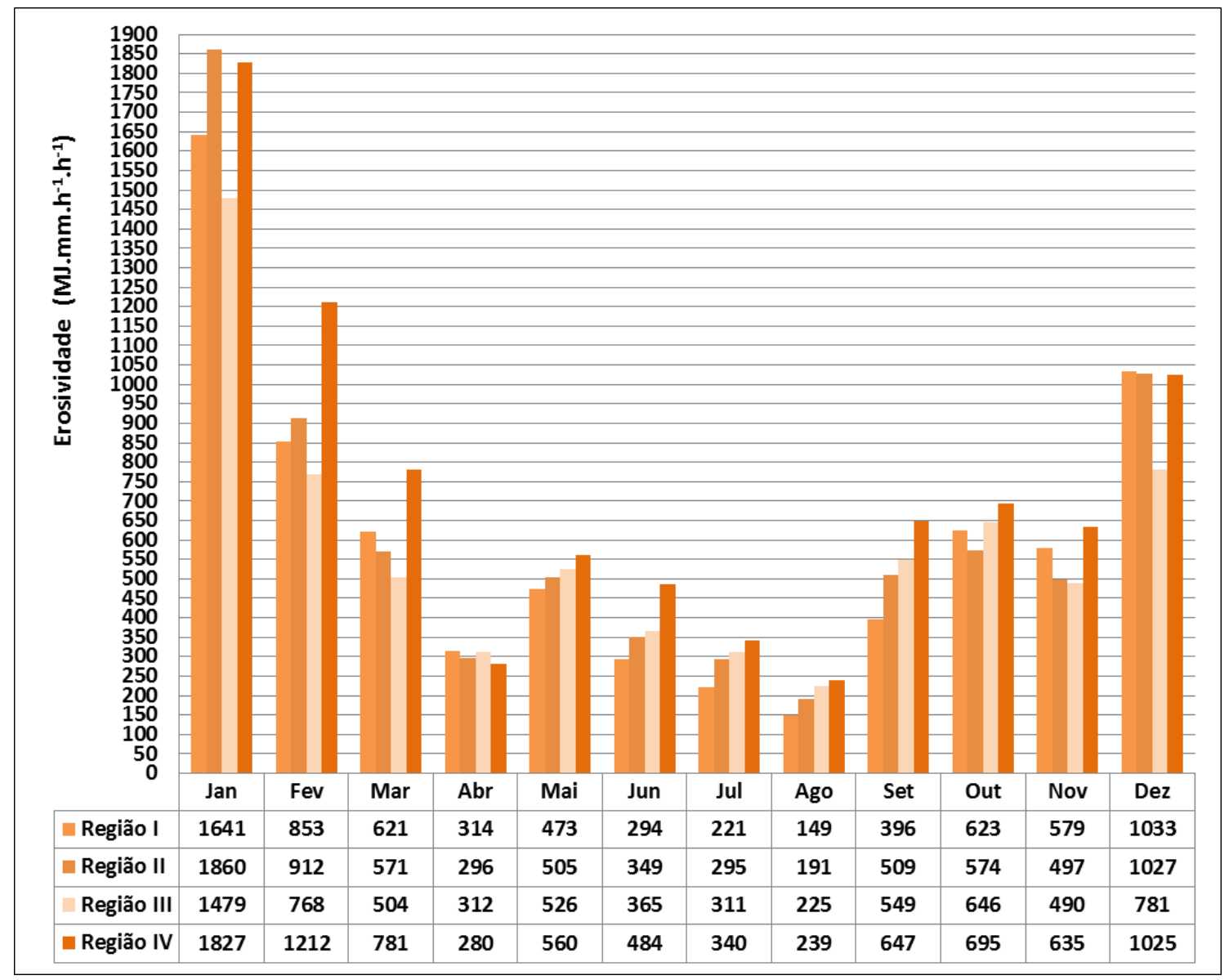

Figura 7 - Distribuição mensal da erosividade média mensal (MJ.mm.ha-1.h 1.mensal-1) para as regiões (zonas) climáticas na bacia hidrográfica do rio Itararé - PR.

Quanto ao regime térmico, a zona climática I caracteriza-se pela maior temperatura média anual $\left(20,2^{\circ} \mathrm{C}\right)$, a maior evapotranspiração potencial anual $(961,7 \mathrm{~mm})$ e menor média anual do excedente hídrico (411,2 mm) (Figuras 8 e 9). Por situar-se no setor norte da área de estudo, essa zona climática caracteriza-se pelos maiores valores mensais de evapotranspiração potencial, que aliada a maior redução da pluviosidade nos meses de outono e inverno, demonstrando de forma mais notável a tropicalização climática (SILVA et al., 2006), com a redução dos valores de excedente hídrico nos períodos de outono e inverno, e mostrando a possibilidade de ocorrência de deficiência hídrica nos meses e abril e agosto (Figura 10). 
Com o aumento da altitude, a zona climática II apresenta uma redução da temperatura média anual $\left(18,6^{\circ} \mathrm{C}\right)$ e uma redução da evapotranspiração potencial anual $(864,1 \mathrm{~mm})$ e uma média anual do excedente hídrico de 628,2 $\mathrm{mm}$. Desta forma, observa-se que a zona climática II beneficia-se do aumento de pluviosidade e da redução térmica, condições resultantes da combinação entre orografia e dinâmica atmosférica, para a obtenção do maior excedente hídrico, comparativamente entre as zonas climáticas I e III (Figuras 8 e 9).

O setor de maior hipsometria na área de estudo compreende a zona climática III, com uma altitude média de 1046 metros. Esse aspecto, junto a sua proximidade com o domínio climático subtropical, determina as estimativas de menores médias térmicas anuais $\left(17,9^{\circ} \mathrm{C}\right)$ e o menor potencial da evapotranspiração potencial anual $(822,9 \mathrm{~mm})$. Com a redução da pluviosidade média anual, verificase que a zona climática III apresenta uma pequena redução do excedente hídrico anual em relação à zona climática II, equivalente a 606,0 mm (Figuras 8 e 9).

Comparativamente, observa-se que a zona climática II apresenta maiores valores de excedente hídrico nos meses de janeiro, fevereiro, março e dezembro, ao passo que a zona climática III obteve por maiores valores de excedente hídrico nos demais meses, com menores disparidades durante aqueles que se caracterizam pelo outono e inverno. Justamente pelas mesmas características observadas para a pluviosidade média mensal, a zona climática II mostrou que o setor central da bacia hidrográfica apresenta as maiores elevações de pluviosidade e excedente hídrico devido à sua localização transicional e maior interação entre sistemas atmosféricos intertropicais e extratropicais. Por sua vez, a zona climática III delimita a região de características tipicamente subtropicais, com uma maior regularidade do regime pluviométrico e menores acréscimos das chuvas nos meses de verão (Figura $10)$.

Com menores cotas altimétricas (818 metros), a zona climática IV apresenta um aumento da média térmica anual $\left(19,3^{\circ} \mathrm{C}\right)$ e um aumento da evapotranspiração potencial anual (888 mm). Mesmo com maiores médias térmicas e maiores valores de evapotranspiração potencial, essa região compreende o 
setor de maior excedente hídrico médio anual $(899 \mathrm{~mm})$, justamente pelo elevado acréscimo de pluviosidade em relação às demais porções da bacia hidrográfica (Figuras 8 e 9).

A zona climática IV apresenta majoritariamente os valores mais elevados do excedente hídrico mensal. Sua proeminência como setor de maior excedente hídrico se atribui a condição predominante de maior pluviosidade, por situar-se em uma região limite de influência do efeito orográfico, uma vez que se verificou que a partir de maiores elevações a condição térmica reduz a probabilidade de chuvas convectivas (Figura 10).

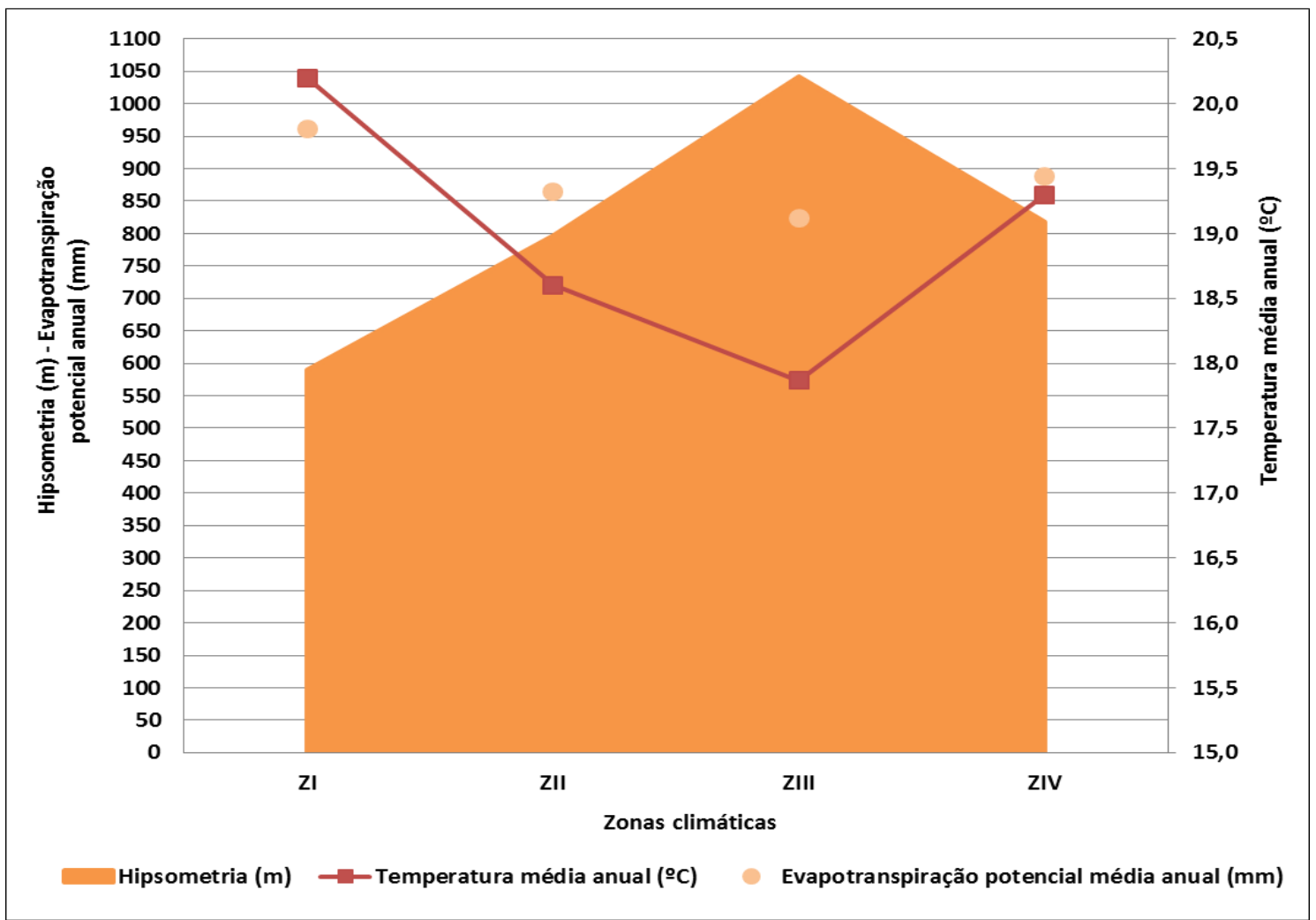

Figura 8 - Distribuição da temperatura média anual $\left({ }^{\circ} \mathrm{C}\right)$ e evapotranspiração potencial anual (mm) conforme a altimetria e a zona climática da bacia hidrográfica do rio Itararé - PR. 


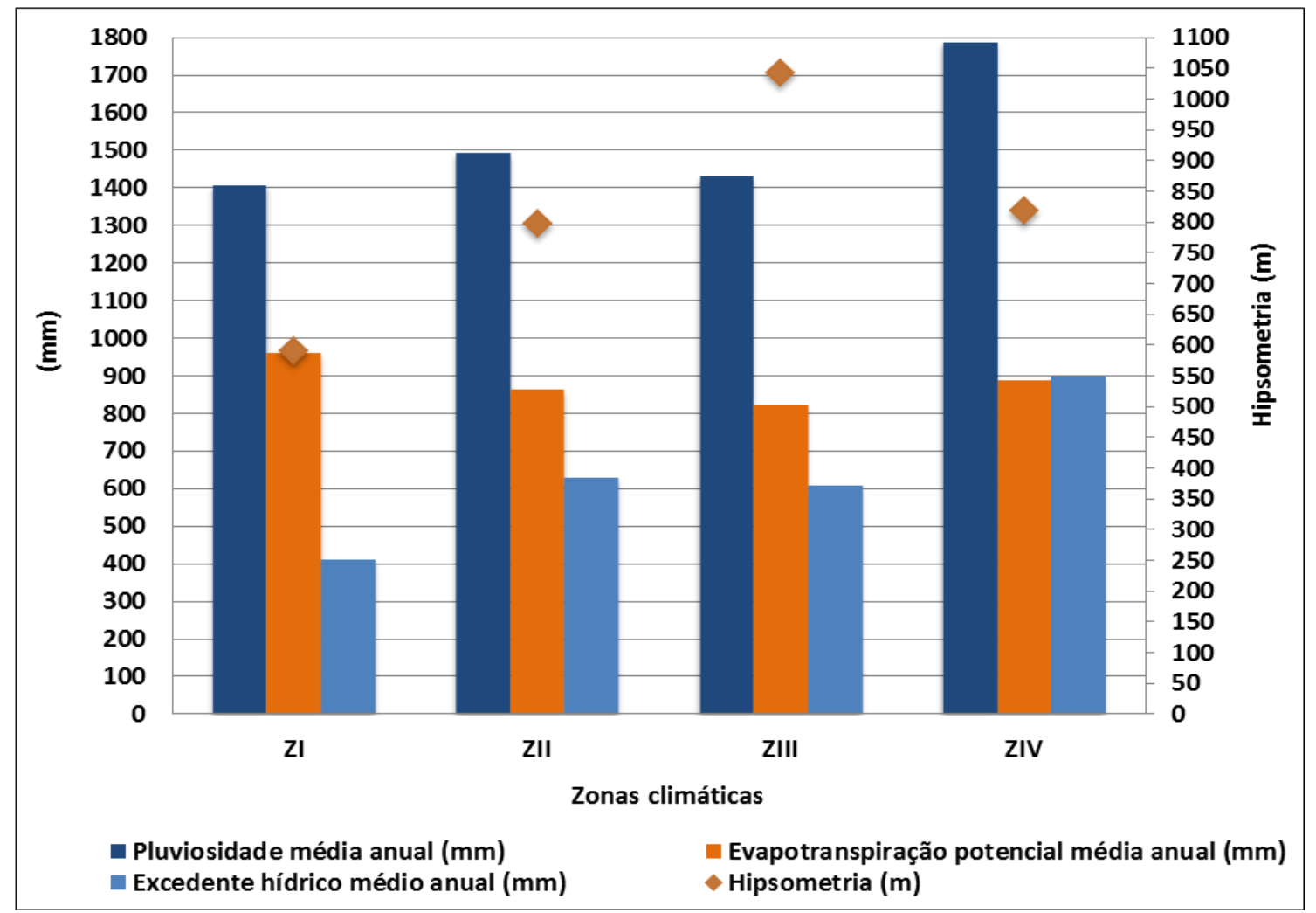

Figura 9 Distribuição da pluviosidade média anual $(\mathrm{mm})$ e erosividade média anual conforme a altimetria e a zona climática da bacia hidrográfica do rio Itararé - PR.

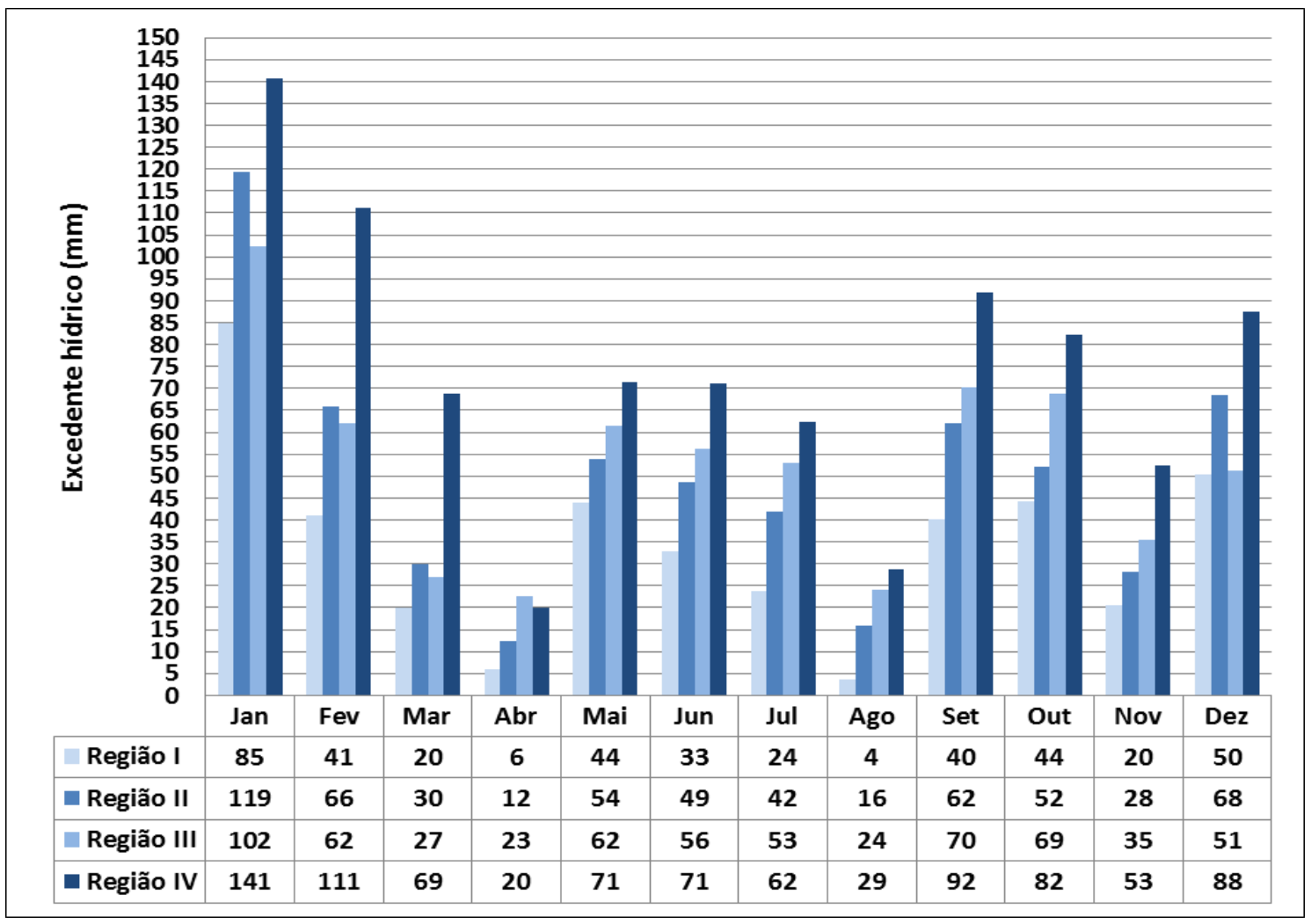

Figura 10 - Distribuição mensal do excedente hídrico para as regiões (zonas) climáticas da bacia hidrográfica do rio Itararé - Paraná. 
As informações discorridas permitem avaliar que a área de estudo apresenta maiores potenciais a ocorrência à deficiência hídrica nos setores setentrionais, nas proximidades da represa de Chavantes, com uma redução gradativa em direção a nascente do curso principal do rio Itararé, de maiores excedentes hídricos. Esse panorama revela, em linhas gerais, as relações existentes entre os componentes da dinâmica climática regional, uma vez que a redução de pluviosidade nos meses de outono e inverno é mais significativa ao norte, o que se torna preponderante com as maiores médias térmicas em comparação às demais porções da área de estudo. Ao sul, com o aumento da altimetria, a provável maior atuação dos sistemas atmosféricos extratropicais e, consequentemente, as menores temperaturas e a menor redução de totais pluviométricos, indicam um quadro mais desfavorável à deficiência hídrica.

As características físicas e humanas da vertente paranaense da bacia hidrográfica do rio Itararé são altamente relevantes para justificar o zoneamento climático desse recorte espacial. Conforme observado por Terassi (2015), a diversidade de formações litológicas junto ao elevado declive predominante na área de estudo resultou na formação de solos que naturalmente apresentam elevada susceptibilidade aos processos erosivos e que, somados a elevada porção ocupada por atividades agrossilvipastoris, ressaltam a necessidade de compreensão do regime de chuvas e sua associação com o potencial erosivo (Figura 11).

Por sua vez, o levantamento da cobertura vegetal e do uso da terra indicou que da vegetação original da bacia hidrográfica somente uma pequena porção foi mantida, sendo largamente substituída pela ocupação de plantio de pastagens e lavouras, demonstrando a imprescindibilidade do conhecimento de características hídricas, como a evapotranspiração potencial e real, e o excedente e a deficiência hídrica, para o subsídio ao planejamento dessas atividades (Figura 11).

Destaca-se que as zonas climáticas I e II apresentam elevado potencial de erosividade das chuvas, principalmente pela grande concentração de pluviosidade nos meses de verão, e a significativa utilização do solo pela agricultura e a pecuária. A zona climática I merece destaque quanto ao elevado potencial erosivo das chuvas por encontrar-se próximo ao reservatório de Chavantes, pois indica maior 
susceptibilidade a gênese e desenvolvimento de processos erosivos marginais. Especialmente, a zona climática IV compreende um setor que requer cuidados, haja vista as características de cobertura pedológica, as grandes porções de solo exposto e os maiores valores de erosividade das chuvas (Figura 11). Conforme indicado pela figura 5, as três regiões mencionadas acima apresentam as maiores preocupações com relação ao potencial erosivo das chuvas, sobretudo por terem sido identificados tais setores uma média de 1.000 MJ.mm.ha.-1h.-1.mês-1 para os meses de janeiro e dezembro, que segundo Silva (2004) e Oliveira et al. (2010), são os meses de maior potencial erosivo em praticamente todo território brasileiro.

O zoneamento climático permitiu estabelecer que os setores setentrionais, mais próximos ao marco delimitativo do trópico de capricórnio, apresentam características mais próximas ao clima tropical, de maiores médias térmicas e redução de chuvas durante o inverno. Portanto, as zonas climáticas I e II, principalmente a primeira, caracterizam-se por maior tendência à ocorrência de eventos de deficiência hídrica. Trata-se de uma condição que merece destaque, uma vez que estas são as porções da área de estudo que apresentam o uso mais incisivo do solo para a pastagem e as lavouras temporárias. As zonas climáticas III e IV, por apresentarem menores temperaturas evapotranspiração potencial, se destacam pelo maior excedente hídrico. As diferenças do regime hídrico entre as quatro zonas climáticas obtidas para o presente recorte de estudo são concordantes com os resultados de Wrege et al. (2016), que observaram uma maior deficiência hídrica no período de inverno no sentido norte do Estado do Paraná. 


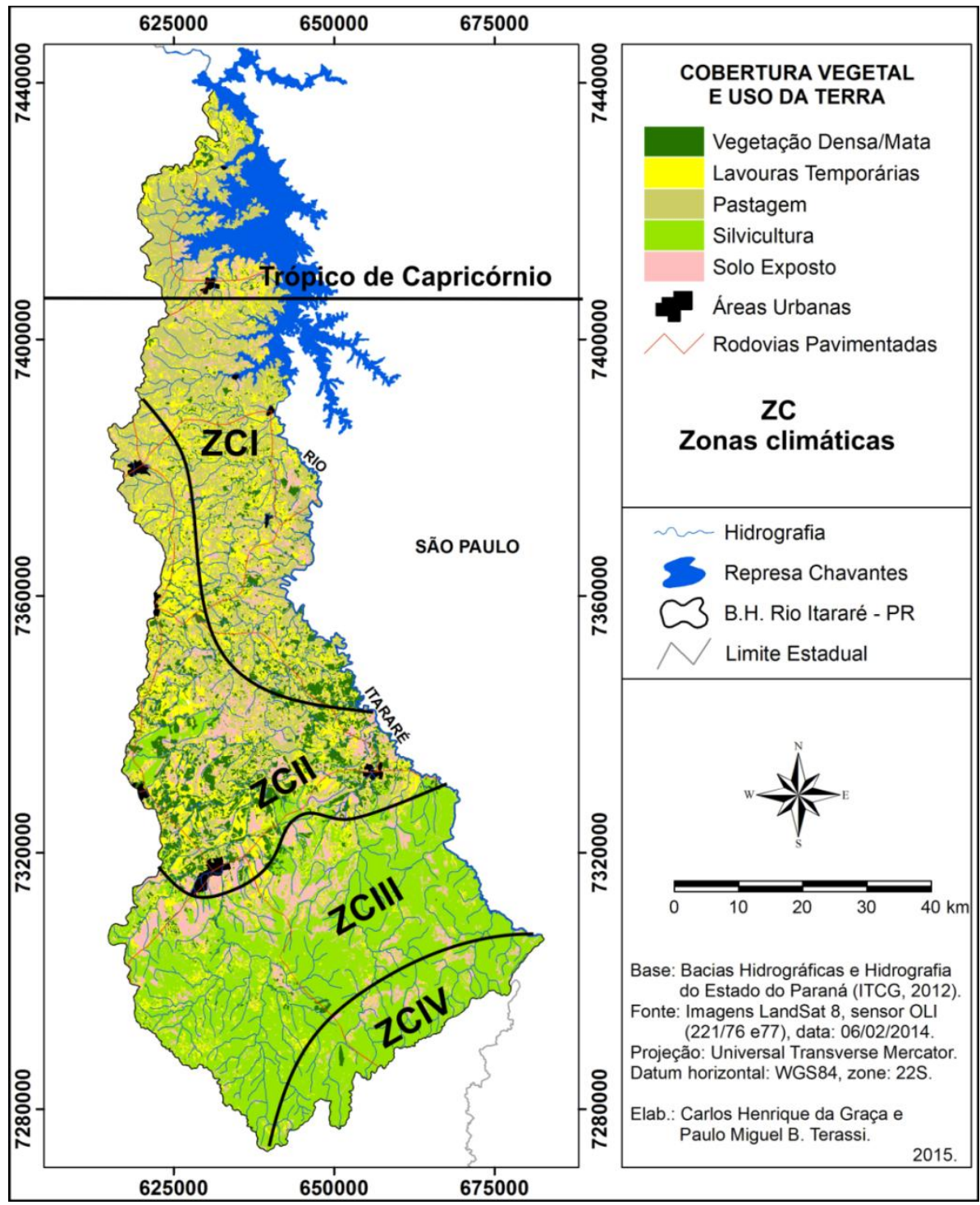

Figura 11 - Cobertura vegetal e uso da terra e as zonas climáticas na bacia hidrográfica

\section{CONSIDERAÇÕES FINAIS}

Verificou-se que a relação proporcional entre o total de pluviosidade e o número de dias de chuva responde pela distribuição espacial do potencial erosivo e permitiu avaliar uma provável atuação da participação dos fatores climáticos para a geração das chuvas. Especialmente nas margens do reservatório de Chavantes, representado pelas zonas climáticas I e II, verificam-se os maiores problemas com a erosividade, principalmente pelo elevado acréscimo de chuvas no trimestre de verão. A zona climática IV apresenta a maior erosividade, que junto à verificação de solo exposto associado a elevadas declividades, correspondem a fatores de maior suscetibilidade à erosão. 
O zoneamento climático representativo dos atributos temperatura, precipitação, evapotranspiração potencial e excedente hídrico mostraram que as zonas meridionais apresentam a maior disponibilidade hídrica pelo decréscimo da evapotranspiração potencial com a maior regularidade da marcha anual da pluviosidade. Como efeito da tropicalização climática, verificou-se que o setor norte, na zona climática I, destaca-se com os menores excedentes hídricos mensais e a maior probabilidade de deficiência hídrica. A região norte da área de estudo apresenta a significativa ocupação por pastagens e lavouras temporárias e, o alerta da possibilidade de deficiência hídrica, especialmente em meses como abril e agosto, por demonstrarem uma vulnerabilidade a essas atividades econômicas.

\section{REFERÊNCIAS}

APARECIDO, L.E.O.; ROLIM, G.S.; RICHETTI, J.; SOUZA, P.S.; JOHANN, J.A. Köppen, Thornthwaite and Camargo climate classifications for climatic zoning in the State of Paraná, Brazil. Ciência e Agrotecnologia (Online), Lavras, v.40, n.4, p.405-417, 2016.

CORREA, M.G.G. Distribuição espacial e variabilidade da precipitação pluviométrica na bacia do rio Piquiri - PR. 2013.102f. Dissertação (Mestrado). Programa de Pós-Graduação em Geografia Física, Universidade de São Paulo, São Paulo, 2013.

CAMARGo, A. P.; CAMARGO, M. B. P. Uma revisão analítica da evapotranspiração potencial. Bragantia, Campinas, v.59, n.2, p.125-137, 2000.

CLARKE, R.T.; SILVA, B.C. Análise estatística de chuvas intensas na bacia do rio São Francisco. Revista Brasileira de Meteorologia, São Paulo, v.19, n.3, p.265-272, 2004.

EMBRAPA (Empresa Brasileira de Pesquisa Agropecuária). Mapa de Solos do estado do Paraná. Rio de Janeiro, Centro Nacional de Pesquisa de Solos: EMBRAPA: Solos e Florestas, ISSN 1517-2627, 2007. 95p.

FRITZSONS, E.; MANTOVANI, L. E.; WREGE, M. S.; CHAVES NETO, A. Análise da pluviometria para definição de zonas homogêneas no estado do Paraná. RA’E GA: o Espaço Geográfico em Análise, Curitiba, v.23, n.1, p.555-572, 2011.

INPE (Instituto de Pesquisas Espaciais). Projeto TOPODATA. 2011. Disponível em:

$<$ http://www.dsr.inpe.br/topodata/ >. Acesso em 22 de julho de 2014.

ITCG (Instituto de Terras, Cartografia e Geodésia). Produtos Cartográficos. Disponível em: $<$ http://www.itcg.pr.gov.br/modules/conteudo/conteudo. php?conteudo= 47. Acesso em 14 de julho de 2014.

KELLER FILHO, T; ASSAD, E.D.; LIMA, P.R.S.R. Regiões pluviometricamente homogêneas no Brasil. Revista Brasileira de Pesquisa Agropecuária, Brasília, v.40, n.4, p.311-322, 2005.

KÖPPEN, W. Climatologia: con un estudio de los climas de la tierra. Fondo de Cultura Econômica. México. 1948. 479p. 
MAACK, R. Geografia Física do estado do Paraná. 4ª Edição. Ponta Grossa: Editora UEPG. 2012. 526p.

MINEROPAR. Atlas Geológico do Estado do Paraná. 2001. Minerais do Paraná, Curitiba. 2001. 125p. CD ROM.

NIMER. E. Climatologia do Brasil. 2ªEdição. Rio de Janeiro: Instituto Brasileiro de Geografia e Estatística, 1989. 421p.

OMETTO, J. C. Bioclimatologia vegetal. São Paulo, Ed. Agronômica Ceres, 1981, 425p.

OLIVEIRA, L.F.C.; FIOREZE, A.P.; MEDEIROS, A.M.M.; SILVA, M.A.S. Comparação de metodologias de preenchimento de falhas em séries históricas de precipitação pluvial anual. Revista Brasileira de Engenharia Agrícola e Ambiental, Campina Grande, v.14, n.11, p.1186-1192, 2010.

OLIVEIRA, P.T.S.; WENDLAND, E.; NEARING, M.A. Rainfall erosivity in Brazil: a review. Catena, Amsterdam, v.100, n.1, p.139-147, 2012.

PEREIRA, A.R. Simplificando o Balanço Hídrico de Thornthwaite - Mather. Bragantia, Campinas, v.64, n.2, p.311-313, 2005.

RUFINO, R. L.; BISCAIA, R. C. M.; MERTEN, G. H. Determinação do potencial erosivo da chuva do estado do Paraná, através de pluviometria: terceira aproximação. Revista Brasileira de Ciência do Solo, v.17, n.1, p.439-444,1993.

ROLIM, G. S.; SENTELHAS, P. C.; BARBIERI, V. Planilhas no ambiente EXCEL para os cálculos de balanços hídricos: normal, sequencial, de cultura e de produtividade real e potencial. Revista Brasileira de Agrometeorologia, Santa Maria, v.6, p.133-137, 1998.

SANT'ANNA NETO, J.L. Da climatologia geográfica à geografia do clima: gênese, paradigmas e aplicações clima como fenômeno geográfico. Revista da ANPEGE, Uberlândia, v.4, n.1, p. 51-72, 2008.

SANTOS, R. F. Planejamento Ambiental: teoria e prática. 1aㅡㄹição. São Paulo: Oficina de Textos, 2004.184p.

SILVA, A.M. Rainfall erosivity map for Brazil. Catena, Amsterdam, v.57, n.3, p.251-259. 2004.

SILVA, C. B.; SANT’ANNA NETO, J. L.; TOMMASELLI, J. T. G.; PASSOS, M. M. Dinâmica atmosférica e análise geoestatística do clima na área de integração paisagística 'Raia Divisória' SP/PR/MS: uma proposta de tipologia climática. Revista Brasileira de Climatologia, Curitiba, v.2, n.1, p. 53-70, 2006.

TEODORO, P.E.; DE OLIVEIRA-JÚNIOR, J.F.; DA CUNHA, E.R.; CORREA, C.C. G.; TORRES, F.E.; BACANI, V.M.; GOIS, G.; RIBEIRO, L.P. Cluster analysis applied to the spatial and temporal variability of monthly rainfall in Mato Grosso do Sul State, Brazil. Meteorology and Atmospheric Physics, Berlin, v.128, n.6, p.197-209, 2015.

TERASSI, P.M.B. Estudo de parâmetros climáticos como subsídio à gestão ambiental da vertente paranaense do rio Itararé. 2015. 149f. Dissertação (Mestrado). Programa de Pós-Graduação em Geografia, Universidade Estadual Paulista "Júlio de Mesquita Filho", Presidente Prudente, 2015.

TERASSI, P. M. B.; TOMMASELLI, J.T.G. Caracterização termo-pluviométrica e a classificação climática para a vertente paranaense da bacia hidrográfica do rio Itararé. Formação, Presidente Prudente, v.2, n.22, p.169-191, 2015.

THORNTHWAITE, C. W.; MATHER, J.R. The water balance climatology. Centerion, v.8, n.1, p.1-86, 1955.

UDEL (University of Delaware). Air temperature and precipitation. 2014. Disponível em: <

http://www.esrl.noaa.gov/psd/data/gridded/data.UDel_AirT_Precip.ht

$\mathrm{ml}>$. Acesso em 12 de maio de 2014. 
VILlelA, S. M.; MATTOS, A. Hidrologia aplicada. São Paulo: McGraw-Hill do Brasil, 1975. 245p.

VITTE, A. C.; MELLO, J. P. Erodibilidade dos solos e morfogênese de vertentes. CLIMEP - Climatologia e estudos da paisagem, Rio Claro, v.2, n.2, p. 23-38, 2007.

WALTRICK, P. C.; MACHADO, M. A. M.; DIECKOW, J.; OLIVEIRA, D. Estimativas da erosividade de chuvas no estado do Paraná pelo método da pluviometria: Atualização com dados de 1986 a 2008. Revista Brasileira de Ciência do Solo, Viçosa, v.39, n.1, p.256-267, 2015.

WREGE, M. S.; FRITZSONS, E.; CARAMORI, P.H.; RICCE, W.S.; RADIN, B.; STEINMETZ, S.; REISSER JÚNIOR, C. Regiões com similaridade de comportamento hídrico no Sul do Brasil. RA'E GA: o Espaço Geográfico em Análise, Curitiba, v.38, p.363-382, 2016. 